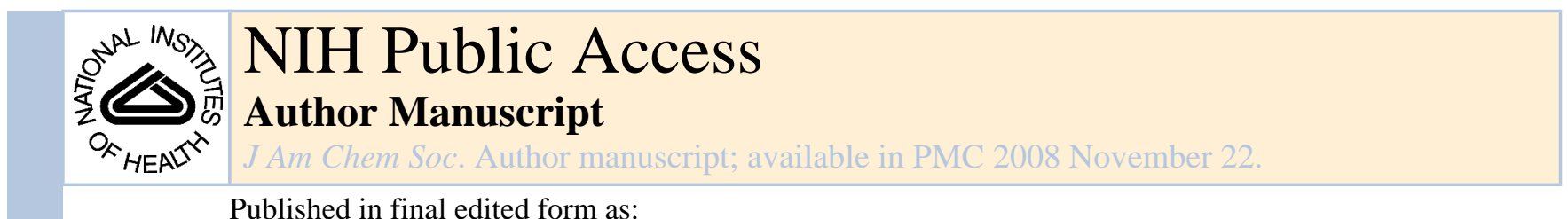

Published in final edited form as:

J Am Chem Soc. 2007 April 18; 129(15): 4508-4509. doi:10.1021/ja068189n.

\title{
Nucleophilic Acylation of o-Quinone Methides: An Umpolung Strategy for the Synthesis of $\alpha$-Aryl Ketones and Benzofurans
}

\author{
Anita E. Mattson and Karl A. Scheidt ${ }^{*}$ \\ Department of Chemistry, Northwestern University, 2145 Sheridan Road, Evanston, Illinois 60208
}

The inversion of normal reactivity patterns, or Umpolung, enables the development of unconventional bond-forming strategies for the synthesis of biologically active target molecules. ${ }^{1}$ The generation of acyl anion equivalents by the polarity reversal of carbonyl functional groups is one valuable Umpolung tactic. Given our interest in unconventional bondforming strategies, ${ }^{2}$ we decided to concentrate on developing an acyl anion approach to synthesize $\alpha$-aryl ketones. The preparation of $\alpha$-aryl ketones is a challenging goal and the majority of recent progress has focused on the development of transition metal-catalyzed couplings of enolates and aryl halides. ${ }^{3}$ Herein, we report the direct synthesis of $\alpha$-aryl ketones (3) by the fluoride promoted addition of protected thiazolium carbinols (1) to quinone methides that are generated in situ from silyl protected phenols (2, eq 1).

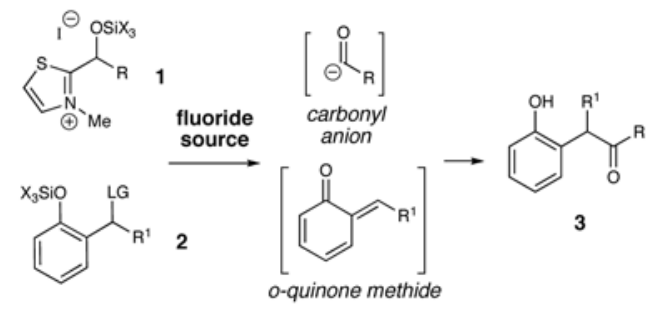

We recently disclosed that fluoride promotes the nucleophilic acylation of nitroalkenes when stable $O$-silyl thiazolium carbinols (1) are employed as carbonyl anion precursor. ${ }^{4}$ Interestingly, Rokita has reported that $O$-silylated phenols (such as 2) produce $o$-quinone methides when exposed to fluoride. 5,6 We envisioned that combining compounds with the general structures of $\mathbf{1}$ and $\mathbf{2}$ with an appropriate fluoride source would simultaneously generate the corresponding carbonyl anion and o-quinone methide species in the same reaction flask. The subsequent combination of the nucleophilic carbonyl anion and electrophilic $o$-quinone methide should provide the desired $\alpha$-aryl ketones $(3)$ in a single operation. ${ }^{7}$ The main challenge with this approach is the simultaneous generation of two highly reactive intermediates.

Our investigations of this new coupling strategy focused on the addition of protected thiazolium carbinol $\mathbf{1 a}$ to $o$-quinone methide precursor $\mathbf{2}$ in the presence of tetramethylammonium fluoride (Table 1, eq 2). ${ }^{8}$ The exposure of $\mathbf{1 a}$ and $\mathbf{2 a}$ to this fluoride source at $-50{ }^{\circ} \mathrm{C}$ afforded an encouraging $43 \%$ yield of the desired $\alpha$-aryl ketone $\mathbf{3}$ (entry 1). Optimization of the reaction conditions revealed that the best yields of $\mathbf{3}$ are obtained with lower temperatures $\left(-78{ }^{\circ} \mathrm{C}, 23\right.$ h) followed by slowly warming to $23{ }^{\circ} \mathrm{C}$ (entry 2) ${ }^{910}$ Another important factor affecting the yield of the reaction is concentration: the optimal value of $0.1 \mathrm{M}$ affords $72 \%$ of $\mathbf{3}$ (entries 2-

scheidt@northwestern.edu. 
4). Although bromide leaving groups on the $o$-quinone methide precursor gives the highest yields, the corresponding benzylic chloride (2b) is also a suitable reaction partner (entry 2 vs. entry 5), albeit in reduced yield (53\%). ${ }^{11}$ To lend support to the intervention of an $o$-quinone methide, a competition experiment was conducted with 1 equiv each of 1a, 2a, and 2-methoxybenzylbromide in the presence of 2 equiv of $\mathrm{Me}_{4} \mathrm{~N} \cdot \mathrm{F}$. Using the reaction conditions from Table 1 , only aryl ketone $\mathbf{3}$ is observed with none of the methyl ether product that would arise from direct alkylation of the carbonyl anion. ${ }^{9}$

With the optimal parameters established for this Umpolung reaction, we turned our attention to investigating the scope of the process (Table 2, eq 3). A brief survey of protected thiazolium carbinols reveals the reaction accommodates additional aromatic substituents (entries 1-3). When carbinols derived from alkyl and $\alpha, \beta$-unsaturated aldehydes are employed as the acyl anion precursor, the desired $\alpha$-aryl ketones are formed in moderate yields (not shown 40-53\%). While these observations are encouraging, further investigations of this new strategy are necessary to accommodate these particular substrates.

An examination of the $o$-quinone methide component of the reaction indicates that variously substituted protected phenols are competent electrophile progenitors. In addition to the unsubstituted methides (e.g. derived from 2 ), alkyl and aryl substitution at $\mathrm{R}^{1}$ provides good yields of the corresponding acylated products (60\% and 68\%, entry 5). Substitution on the phenyl ring is also well tolerated. The quinone methide precursor derived from $o$-vanillin was able to produce the desired $\alpha$-aryl ketone in $68 \%$ yield (entry 6 ). A high yield of product was also observed when the quinone methide precursor $2 \mathbf{f}$ was subjected to the reaction conditions (75\%, entry 7). For certain structures, the benzylic bromide reactants are unstable and could not be easily isolated. For these cases, the corresponding benzylic chlorides can be successfully employed in the reaction (entries 5 and 7).

This fluoride-induced Umpolung strategy can be extended beyond $o$-quinone methides. For example, $\alpha$-indoyl ketone compounds such as $\mathbf{1 2}$ can be accessed in good yield (70\%) from the combination of a silyl protected gramine derivative $\mathbf{1 1}$ and thiazolium carbinol 1a in the presence of 2.5 equivalents of $\mathrm{Me}_{4} \mathrm{~N} \cdot \mathrm{F}$ (Scheme 1). ${ }^{12}$

This new bond-forming process facilitates a total synthesis of the naturally occurring aromatase inhibitor, demethylmoracin I. ${ }^{13}$ In the key step, highly substituted $\alpha$-aryl ketone 14 is prepared in $62 \%$ yield from thiazolium carbinol $\mathbf{1 3}^{\mathbf{9}}$ and $\mathbf{2 f}$ with $\mathrm{Me}_{4} \mathrm{~N} \cdot \mathrm{F}$. The acid-catalyzed cyclization to the corresponding benzofuran $\mathbf{1 5}$ is accomplished in $79 \%$ yield. The prenyl group is installed using a Stille cross coupling reaction and global demethylation with lithium diphenylphosphanide ${ }^{14}$ in refluxing THF affords demethylmoracin I.

In summary, the synthesis of $\alpha$-aryl ketones via the direct nucleophilic acylation of $o$-quinone methides has been reported. In this Umpolung process, a reactive carbonyl anion and $o$-quinone methide are generated in the same flask by addition of fluoride ion and then undergo productive bond formation to yield the desired adducts. Investigations into the utility and applications of thiazolium carbinols as unique acyl anion precursors are ongoing in our laboratory.

\section{Supplementary Material}

Refer to Web version on PubMed Central for supplementary material.

\section{Acknowledgements}

This work has been generously supported by Northwestern, NIH (RO1 GM73072), Abbott Laboratories, Amgen, Boerhinger-Ingelheim, 3M, and Wacker Chemical Corp. A.E.M. acknowledges an ACS Division of Organic 
Chemistry Fellowship sponsored by Eli Lilly. We thank a reviewer for suggesting the competition experiment employing 1a, 2a, and 2-methoxy-benzylbromide with Me4N.F.

\section{References}

1. (a) Grobel BT, Seebach D. Synthesis 1977:357-402. (b) Seebach D. Angew Chem Int Ed 1979;18:239258.

2. (a) Mattson AE, Bharadwaj AR, Scheidt KA. J Am Chem Soc 2004;126:2314-2315. [PubMed: 14982429] (b) Mattson AE, Scheidt KA. Org Lett 2004;6:4363-4366. [PubMed: 15524484] (c) Chan A, Scheidt KA. Org Lett 2005;7:905-908. [PubMed: 15727471] (d) Myers MC, Bharadwaj AR, Milgram BC, Scheidt KA. J Am Chem Soc 2005;127:14675-14680. [PubMed: 16231921]

3. (a) Fox JM, Huang XH, Chieffi A, Buchwald SL. J Am Chem Soc 2000;122:1360-1370. (b) Hamada T, Chieffi A, Ahman J, Buchwald SL. J Am Chem Soc 2002;124:1261-1268. [PubMed: 11841295] (c) Culkin DA, Hartwig JF. Acc Chem Res 2003;36:234-245. [PubMed: 12693921]

4. Mattson AE, Zuhl AM, Reynolds TE, Scheidt KA. J Am Chem Soc 2006;128:4932-4933. [PubMed: 16608309]

5. For a review on o-quinone methides, see: Van de Water RW, Pettus TRR. Tetrahedron 2002;58:53675405.

6. (a) Pande P, Shearer J, Yang JH, Greenberg WA, Rokita SE. J Am Chem Soc 1999;121:6773-6779. (b) Rokita SE, Yang JH, Pande P, Greenberg WA. J Org Chem 1997;62:3010-3012. [PubMed: 11671669] (c) Génisson Y, Tyler PC, Ball RG, Young RN. J Am Chem Soc 2001;123:11381-11387. [PubMed: 11707114] (d) Barrero AF, del Moral JFQ, Herrador MM, Arteaga P, Cortés M, Benites J, Rosellón A. Tetrahedron 2006;62:6012-6017.

7. For a singular example of a lithiated dithiane undergoing an addition to an ortho-oxygenated benzylic halide, see: Tetrahedron Lett 1988;29:6885-6889.

8. (a) Christe KO, Wilson WW, Wilson RD, Bau R, Feng JA. J Am Chem Soc 1990;112:7619-7625. (b) Menand ML, Dalla V. Synlett 2005:95-98.

9. The yield of 3 is lower (45\%) when incubating the reaction at $-78{ }^{\circ} \mathrm{C}$ for $1 \mathrm{~h}$ (vs. $23 \mathrm{~h}$ ) followed by warming to $23{ }^{\circ} \mathrm{C}$.

10. See Supporting Information for details.

11. The combination of $\mathbf{1 a}$ and $\mathrm{Me}_{4} \mathrm{NF}$ with benzyl bromide affords only low yields of benzyl ketone under the best conditions from Table 1 .

12. For examples of fluoride-induced elimination-addition reactions of N-triisopropylsilyl gramine methyliodide, see: Iwao M, Motoi O. Tetrahedron Lett 1995;36:5929-5932.

13. Lee D, Bhat KPL, Fong HHS, Farnsworth NR, Pezzuto JM, Kinghorn AD. J Nat Prod 2001;64:12861293. [PubMed: 11678652]

14. McAllister GD, Hartley RC, Dawson MJ, Knaggs AR. J Chem Soc, Perkin Trans 1 1998:3453-3457. 


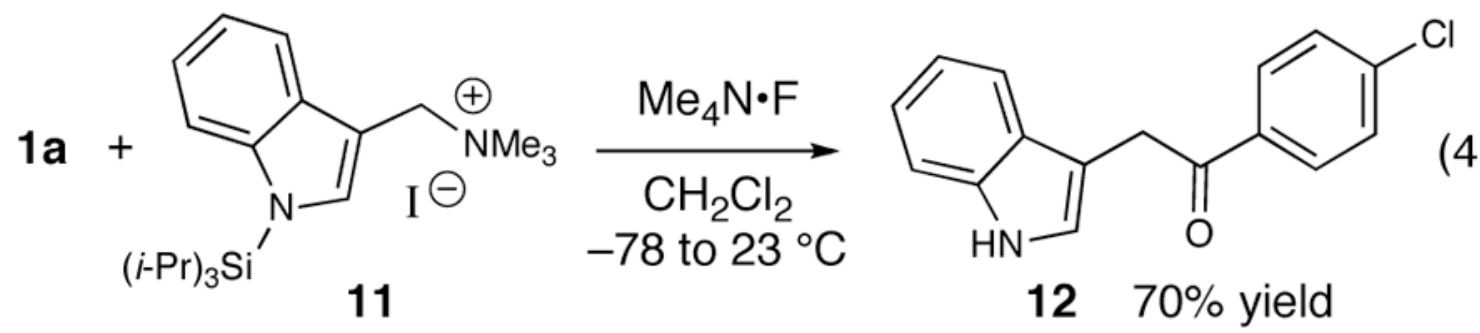

Scheme 1. 
<smiles>COc1ccc(CC(=O)c2cc(OC)cc(OC)c2Br)c(O)c1</smiles>

Scheme 2.

Synthesis of Demethylmoracin I

a. $\mathrm{Me}_{4} \mathrm{~N} \cdot \mathrm{F}, \mathrm{CH}_{2} \mathrm{Cl}_{2},-78$ to $23{ }^{\circ} \mathrm{C}, 62 \%$ b. Amberlyst $15,4 \AA$ sieves, $\mathrm{CH}_{2} \mathrm{Cl}_{2} 79 \%$ c. prenyl tributyltin, $\mathrm{PdCl}_{2}$ (dppf), DMF, $100{ }^{\circ} \mathrm{C}, 76 \%$ d. $n \mathrm{BuLi}, \mathrm{PHPh}_{2}$, THF, $61 \%$. 
Table 1

Optimization of Carbonyl Anion Additions ${ }^{a}$

\begin{tabular}{cccccc}
\hline \\
entry
\end{tabular}

${ }^{a}$ See Supporting Information for details.

$b_{\text {Isolated yield }}$ 


\section{Table 2}

$\alpha$-Aryl Ketones Prepared from Thiazolium Carbinols (1) and Silylated Phenols (2) ${ }^{a}$

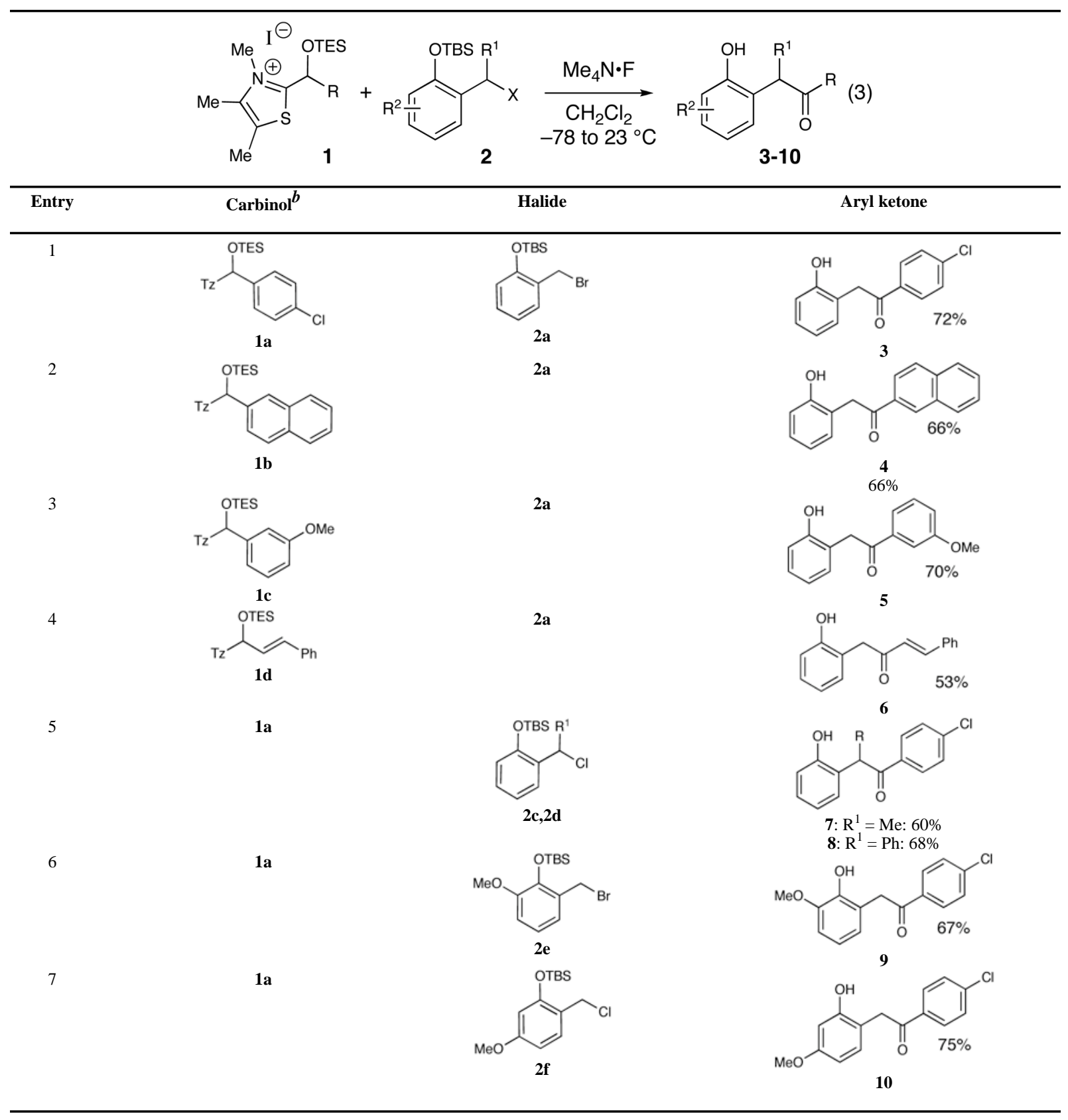

${ }^{a}$ See Supporting Information for reaction details,

${ }^{b} \mathrm{Tz}=$ 2-substituted 3,4,5-trimethylthiazol-3-ium iodide. 